\title{
An Investigation into the Prediction of In Vivo Clearance for a Range of Flavin-containing Monooxygenase Substrates ${ }^{\mathbb{S}}$
}

\author{
Barry C. Jones, Abhishek Srivastava, Nicola Colclough, Joanne Wilson, Venkatesh Pilla Reddy, \\ Sara Amberntsson, and Danxi Li
}

\begin{abstract}
Oncology IMED, Astrazeneca, Cambridge, United Kingdom (B.C.J., N.C., J.W., V.P.R.), DSM Astrazeneca, Cambridge, United Kingdom (A.S.); DSM Astrazeneca, Gothenburg, Sweden (S.A.); and Pharmaron, Beijing, China (D.L.)
\end{abstract}

Received July 3, 2017; accepted August 4, 2017

\begin{abstract}
Flavin-containing monooxygenases (FMO) are metabolic enzymes mediating the oxygenation of nucleophilic atoms such as nitrogen, sulfur, phosphorus, and selenium. These enzymes share similar properties to the cytochrome P450 system but can be differentiated through heat inactivation and selective substrate inhibition by methimazole. This study investigated 10 compounds with varying degrees of FMO involvement to determine the nature of the correlation between human in vitro and in vivo unbound intrinsic clearance. To confirm and quantify the extent of FMO involvement six of the compounds were investigated in human liver microsomal (HLM) in vitro assays using heat inactivation and methimazole substrate inhibition. Under these conditions FMO contribution varied from $21 \%$ (imipramine) to $96 \%$ (itopride). Human hepatocyte and
\end{abstract}

\section{Introduction}

Flavin-containing monooxygenases (FMO) are a major enzyme system mediating oxygenation of nucleophilic atoms typically nitrogen, sulfur, phosphorus, and selenium. FMOs have an important role in the metabolism of exogenous compounds including many drugs but also endogenous compounds such as trimethylamine (Phillips and Shephard, 2008). These enzymes are similar to cytochrome P450s (CYPs) in cellular location and cofactor requirement (oxygen and NADPH). However, FMOs can be differentiated from CYPs by heat inactivation (maximum of 5 minutes at $40-50^{\circ} \mathrm{C}$ in the absence of NADPH) and inhibition by specific competitive substrate inhibitors such as methimazole (Cashman and Zhang, 2006; Taniguchi-Takizawa et al., 2015).

There are five FMOs expressed in humans with the major hepatic enzyme being FMO3, which is regarded as having the greatest role in drug metabolism. FMOs are also expressed in extrahepatic tissue, including lung and kidney with FMO1 the major form expressed in kidney and FMO2 mainly expressed in the lung (Cashman and Zhang, 2006). However, in studies that use hepatocytes and human liver microsomes (HLM) only, clearance by FMO may be underestimated due to the lack of expression of FMO1 and 2 in human liver.

Along with differential tissue distribution, the FMOs also have differing substrate specificity. For instance, the FMO1 active site is reported to

https://doi.org/10.1124/dmd.117.077396.

S This article has supplemental material available at dmd.aspetjournals.org.
HLM intrinsic clearance $\left(\mathrm{CL}_{\text {int }}\right)$ data were scaled using standard methods to determine the predicted unbound intrinsic clearance (predicted $\mathrm{CL}_{\text {int } \mathrm{u}}$ ) for each compound. This was compared with observed unbound intrinsic clearance (observed $\mathrm{CL}_{\text {int u}}$ ) values back calculated from human pharmacokinetic studies. A good correlation was observed between the predicted and observed $C L_{\text {int }}$ using hepatocytes $\left(R^{2}=0.69\right)$, with 8 of the 10 compounds investigated within or close to a factor of 2 . For HLM the in vitro-in vivo correlation was maintained $\left(R^{2}=0.84\right)$ but the accuracy was reduced with only 3 out of 10 compounds falling within, or close to, twofold. This study demonstrates that human hepatocytes and HLM can be used with standard scaling approaches to predict the human in vivo clearance for FMO substrates.

ABBREVIATIONS: ACN, acetonitrile; $\mathrm{AO}$, aldehyde oxidase; $\mathrm{CL}$, clearance; $\mathrm{CL}_{\mathrm{b}}$, blood clearance; $\mathrm{CL}_{\text {int }}$, intrinsic $\mathrm{Clearance} \mathrm{CL}_{\text {int }}$ u, unbound intrinsic clearance; CYP, cytochrome P450; DDI, drug-drug interaction; FA, formic acid; FMO, flavin-containing monooxygenases; fu, unbound fraction in plasma; $\mathrm{fu}_{\mathrm{inc}}$, unbound fraction in the incubation; HLM, human liver microsomes; LC-MS/MS, liquid chromatography-tandem mass spectrometry; $\mathrm{R}_{\mathrm{b} / \mathrm{p}}$, blood/plasma ratio. 
etc. (Di et al., 2013; Grime et al., 2013). The method most routinely used for hepatic metabolic clearance is scaling the unbound intrinsic clearance $\left(\mathrm{CL}_{\mathrm{int}} \mathrm{u}\right)$ from in vitro systems. Hepatocytes or HLM $\mathrm{CL}_{\mathrm{int}} \mathrm{u}$ values are scaled to the in vivo situation using factors for the number of cells or milligram protein per gram liver and the ratio of liver weight to body weight and then applying the well-stirred model (Riley et al., 2005; Di et al., 2013). The observation that these in vitro systems can produce systematic under prediction of in vivo CL can be addressed by use of a regression offset method as described previously (Grime and Riley, 2006). However, although this approach generally works well for CYP it has also been shown not to work well for other enzymes substrates such as aldehyde oxidase $(\mathrm{AO})$ where the in vitro data produces a significant under predication of the in vivo CL (Zientek et al., 2010).

FMO activity in hepatocytes has been demonstrated using benzydamine as marker substrate (Fisher et al., 2002). In this study, rat and human hepatocytes were used to predict in vivo blood clearances $\left(\mathrm{CL}_{\mathrm{b}}\right)$ using the scaling methodology described above. In this case, the in vivo $\mathrm{CL}$ in rat was predicted well from the in vitro $\mathrm{CL}_{\text {int }}$ (within $30 \%$ of the measured value), whereas there was an over prediction of the human CL [>10.5 vs. 2.4 $(\mathrm{ml} / \mathrm{min}) / \mathrm{kg}$. However, this is for only one compound and to date there has not been a comprehensive assessment of FMO scaling using a series of substrates with differing FMO contributions.

The aim of this study was to use human in vitro data to predict the CL for a set of compounds for which all or part of the in vivo CL has been determined to be mediated by FMO.

\section{Materials and Methods}

Pooled (150 donors; equal sex mix) HLM were obtained from BD Biosciences (Oxford, UK). Human hepatocytes (mixed sex, 10 donors) were obtained from BioreclamationIVT (Baltimore, MD). Frozen human plasma (mixed sex, 78 individuals) generated using K2-EDTA anticoagulant was purchased from BioreclamationIVT. Coculture of the five-donor human hepatocyte pool (lot 1410235; XenoTech (Kansas City, KS)) and nonparenchymal stromal cells (stromal cell type and ratio of hepatocyte per stromal cell are proprietary information) in type I collagen-coated 96-well plates and H $\mu$ REL PlatinumHeps medium were purchased from H $\mu$ REL (North Brunswick, NJ). FMO substrates benzydamine, tozasertib, itopride, imipramine, clozapine, moclobemide, cimetidine, tamoxifen, ranitidine, and olanzapine used in this study were all synthesized internally at AstraZeneca (Cambridge, UK). $\beta$-Nicotinamide adenine dinucleotide 2 -phosphate reduced tetrasodium salt (NADPH), methimazole, verapamil, formic acid (FA), ammonium formate, and dimethylsulfoxide were purchased from Sigma-Aldrich (Poole, UK). L-15 medium, methanol, water, and acetonitrile (ACN) were HPLC grade from Thermo Fisher Scientific (Hemel Hempstead, UK). All the other solvents were HPLC grade and, unless otherwise specified, all of the other reagents were purchased from Sigma-Aldrich.

Unless otherwise indicated all experiments were conducted in triplicate.

\section{HLM CL $L_{\text {int }}$ Incubations}

Compounds (1 $\mu \mathrm{M}$ final concentration) were incubated with $\operatorname{HLM}(1 \mathrm{mg} / \mathrm{ml})$ in $100 \mathrm{mM}$ phosphate buffer $(\mathrm{pH} 7.4)$ at $37^{\circ} \mathrm{C}$. After a 5-minute preincubation in the presence of NADPH $(1 \mathrm{mM})$, the reaction was initiated by the addition of the compound in $\mathrm{ACN}(<1 \%$ final concentration). Samples $(20 \mu \mathrm{l})$ were removed from the incubation at $0.5,5,10,15,20$, and 30 minutes and added to $100 \mu \mathrm{l}$ of cold ACN containing internal standard. The samples were then centrifuged at $4000 \mathrm{rpm}$ and $4^{\circ} \mathrm{C}$ for 20 minutes to sediment the precipitated proteins before quantitation using liquid chromatography-tandem mass spectrometry (LCMS/MS). The kinetic data were analyzed using a linear fit of the natural logarithm of the ratio of the compound peak area to the internal standard peak area against time. $\mathrm{CL}_{\text {int }}$ values were then calculated from the negative slope of the linear fit divided by the microsomal concentration.

\section{Hepatocytes $\mathbf{C L}_{\text {int }}$ Incubations}

The hepatocytes were thawed and resuspended in prewarmed L-15 medium to give a concentration of $1.0 \times 10^{6}$ viable cells $/ \mathrm{ml}(>80 \%$ viability). The incubations were performed in duplicate in a 96-well plate and the reaction initiated by addition of the compound in $\mathrm{ACN}(<1 \%$ final concentration) to give a final concentration of $1 \mu \mathrm{M}$. The plate was incubated at $37^{\circ} \mathrm{C}$, and $20 \mu \mathrm{l}$ samples were removed at $0.5,5,15,30,45,60,80,100$, and 120 minutes and added to $100 \mu \mathrm{l}$ of cold ACN (containing internal standard). The samples were then centrifuged at $4000 \mathrm{rpm}$ at $4^{\circ} \mathrm{C}$ for 20 minutes before quantitation using LC-MS/MS. The kinetic data were analyzed using a linear fit of the natural logarithm of the ratio of the compound peak area to the internal standard peak area against time. $\mathrm{CL}_{\text {int }}$ values were then calculated from the negative slope of the linear fit divided by the number of hepatocytes.

\section{H $\mu$ REL Low $\mathrm{CL}_{\text {int }}$ Incubations}

If the hepatocyte $\mathrm{CL}_{\text {int }}$ was $<1(\mu \mathrm{l} / \mathrm{min}) / 10^{6}$ cells, then a low intrinsic clearance assay using the H $\mu$ REL primary human hepatocyte coculture system was used. This methodology has been described in detail previously (Bonn et al., 2016). Briefly, coculture plates at a seeding density of 30,000 hepatocytes per well were shipped in $\mathrm{H} \mu$ REL PlatinumHeps shipping medium at $37^{\circ} \mathrm{C}$ from $\mathrm{H} \mu$ REL. On arrival, the shipping medium was replaced with PlatinumHeps maintenance medium and the cells left to acclimatize overnight in incubator at $37^{\circ} \mathrm{C}$ in humidified atmosphere containing $95 \%$ air and $5 \% \mathrm{CO}_{2}$. Before the incubation the cells in each well were washed with $100 \mu \mathrm{H} H \mu$ REL PlatinumHeps dosing medium, which was aspirated and replaced with $50 \mu \mathrm{l}$ of fresh media before the addition of the test compound, which was added in $50 \mu 1 \mathrm{H} \mu$ REL PlatinumHeps dosing medium (final concentration $1 \mu \mathrm{M}$ with $<1 \% \mathrm{ACN}$ ). Samples $(45 \mu \mathrm{l}$ ) were taken at six time points $(1,3,5,24,48$ and 70 hours $)$ and added to $180 \mu \mathrm{l}$ icecold acetonitrile. Samples were centrifuged $\left(20\right.$ minutes $\left.4^{\circ} \mathrm{C}, 4000 \mathrm{~g}\right)$, and $50 \mu \mathrm{l}$ of the supernatant was diluted within $100 \mu \mathrm{l}$ water before LC-MS/MS analysis. The kinetic data were analyzed using a linear fit of the natural logarithm of the compound peak area against time. $\mathrm{CL}_{\text {int }}$ values were then calculated from the negative slope of the linear fit divided by the hepatocyte concentration.

\section{HLM Incubations for Determination of FMO Contribution}

For heat inactivation of FMO, HLM were heated using a thermal cycler that was set to start at $4^{\circ} \mathrm{C}$ and programmed to heat to $50^{\circ} \mathrm{C}$ for 1 minute and revert to $4{ }^{\circ} \mathrm{C}$ immediately after. Compounds ( $1 \mu \mathrm{M}$ final concentration) were incubated with control and heat inactivated HLM $(1 \mathrm{mg} / \mathrm{ml})$ in $100 \mathrm{mM}$ phosphate buffer $(\mathrm{pH} 7.4)$ at $37^{\circ} \mathrm{C}$. After a 5-minute preincubation in the presence of NADPH $(1 \mathrm{mM})$ the reaction was initiated by the addition of the compound in $\mathrm{ACN}(<1 \%$ final concentration). In parallel, compounds ( $1 \mu \mathrm{M}$ final concentration) were also incubated with methimazole $(500 \mu \mathrm{M})$ to determine the fraction metabolized by FMO. Incubations were performed for $0,5,10,20,30$, and 50 minutes in a shaking incubator at $37^{\circ} \mathrm{C}$. Reactions were terminated by the addition of four volumes of ice-cold ACN (containing internal standard), vortexed, and centrifuged at $3500 \mathrm{rpm}$ for 10 minutes and samples analyzed by LC-MS/MS. The data were analyzed using a linear fit of the natural logarithm of the ratio of the compound peak area to the internal standard peak area against time. $\mathrm{CL}_{\text {int }}$ values were then calculated from the negative slope of the linear fit divided by the microsomal concentration. The fraction metabolized by FMO was determined by comparing control incubations with incubations where methimazole or heat inactivation was used.

\section{Determination of Unbound Fraction in Human Plasma (fu)}

The extent of binding of compounds to plasma proteins was determined by equilibrium dialysis at a compound concentration of $5 \mu \mathrm{M}$ using the Rapid Equilibrium Device from Thermoscientific Pierce (Hemel Hempstead, UK). Phosphate buffer (100 mM, pH 7.4) was added to the buffer chamber, and $300 \mu \mathrm{l}$ of plasma with compound to the sample chamber. The unit was covered with a gas permeable lid and incubated for 18 hours at $37^{\circ} \mathrm{C}$ at $300 \mathrm{rpm}$ with $5 \% \mathrm{CO}_{2}$. At the end of incubation, samples $(50 \mu \mathrm{l})$ from both buffer and plasma chambers were removed for analysis. Samples and standards were matrix matched and analyzed using LC-MS/MS. The unbound fraction in plasma (fu) was calculated as follows:

$$
\mathrm{fu}=\text { Conc. } \text { buffer chamber } / \text { Conc. plasma chamber }
$$

\section{Determination of Unbound Fraction in HLM $\left(\mathbf{f u}_{\text {inc }}\right)$}

The extent of binding of compounds to HLM was determined by equilibrium dialysis using the HTDialysis LLC device (Gales Ferry, CT) with HLM at a 
concentration of $1 \mathrm{mg} / \mathrm{ml}$ and a final compound concentration of $1 \mu \mathrm{M}$. Phosphate-buffered saline $(150 \mu \mathrm{l})$ was added to the buffer well and $150 \mu \mathrm{l}$ HLM containing the compound to the sample well and incubated at $37^{\circ} \mathrm{C}$ for 4 hours. After the incubation, 50- $\mu \mathrm{l}$ aliquots from both donor and receiver wells were removed for analysis. Samples and standards were matrix matched and analyzed by LC-MS/MS. The unbound fraction in the incubation ( $\mathrm{fu}_{\mathrm{inc}}$ ) was calculated as follows:

$$
\mathrm{fu}_{\text {inc }}=\text { Conc. } \text { buffer well } / \text { Conc. microsomal suspension well }
$$

\section{Determination of Unbound Fraction in Rat Hepatocytes $\left(\mathbf{f u}_{\mathrm{inc}}\right)$}

The extent of binding of compounds to rat hepatocytes was also determined by equilibrium dialysis using the HTDialysis LLC device. Rat hepatocytes were resuspended with prewarmed L-15 medium at $1.0 \times 10^{6}$ viable cells $/ \mathrm{ml}$. The test compounds, at a final concentration of $1 \mu \mathrm{M}$, were added to the hepatocyte suspension. One hundred and fifty microliters of the hepatocytes suspension containing the compound was added to each of the sample wells of the 96-well dialysis device and phosphate-buffered saline $(150 \mu \mathrm{l})$ to the receiver well and incubated at $37^{\circ} \mathrm{C}$ for 4 hours. After the incubation the samples and standards were matrixed matched and analyzed by LC-MS/MS analysis. The unbound fraction $\left(\mathrm{fu}_{\mathrm{inc}}\right)$ was calculated as follows:

$$
\mathrm{fu}_{\mathrm{inc}}=\text { Conc. } \text { buffer well } / \text { Conc. hepatocyte suspension well }
$$

\section{Determination of Blood/Plasma Ratio $\left(\mathbf{R}_{\mathrm{b} / \mathrm{p}}\right)$}

A volume of plasma sufficient for the assay was obtained from whole human blood by centrifugation $\left(3220 \mathrm{~g}\right.$ for 10 minutes at $\left.4^{\circ} \mathrm{C}\right)$. The test compound $(10 \mu \mathrm{M})$ was added to $398 \mu \mathrm{l}$ of the prewarmed human plasma and blood separately and incubated for 30 minutes. After incubation, the blood samples were centrifuged for 10 minutes at $4000 \mathrm{rpm}\left(37^{\circ} \mathrm{C}\right)$ and the plasma samples stored at $37^{\circ} \mathrm{C}$. Aliquots $(400 \mu \mathrm{l})$ of ice-cold acetonitrile containing internal standard were added to $100-\mu 1$ samples of plasma separated from centrifuged whole blood and to reference plasma samples. This was then centrifuged, diluted with distilled water, and analyzed by LC-MS/MS to determine the compound concentration. $\mathrm{R}_{\mathrm{b} / \mathrm{p}}$ was calculated as follows:

$$
\mathrm{R}_{\mathrm{b} / \mathrm{p}}=\text { Conc }_{\text {reference plasma }} / \text { Conc }_{\text {plasma from blood }}
$$

\section{LC-MS/MS Analysis}

The concentration of all compounds in the incubations was determined by LC-MS/MS. An Acquity ultraperformance liquid chromatography system (Waters, Elstree, UK) coupled to a triple-quadrupole mass spectrometer (Xevo TQ-S; Waters, Milford, MA) was used to carry out the sample analysis. The analytes were separated by reverse-phase liquid chromatography using a Waters Atlantis T3, $3 \mu \mathrm{m}, 2.1 \times 50 \mathrm{~mm}$ column (Waters). Mobile phases A and B consisted of water (containing $0.1 \% \mathrm{FA} \mathrm{v} / \mathrm{v}$ ) and $\mathrm{ACN}$ (containing $0.1 \% \mathrm{FA} \mathrm{v} / \mathrm{v}$ ), respectively. The flow rate was held constant at $0.73 \mathrm{ml} / \mathrm{min}$ throughout the gradient run. The initial mobile phase composition of $95 \% \mathrm{~A}$ and $5 \% \mathrm{~B}$ was held for 0.3 minutes. Mobile phase B was then increased linearly to $70 \%$ until 1.5 minutes, followed by further increase to $99 \%$ B until 1.59 minutes. At 1.6 minutes, the composition of $\mathrm{A}$ and $\mathrm{B}$ was reversed to the initial 95\% A and 5\% $\mathrm{B}$ and was held until 2 minutes. Analyte quantitation was achieved by MS-MS detection in positive electrospray ionization mode. The MS operating conditions were as follows: the capillary voltage was $1.14 \mathrm{kV}$ and source offset was $50 \mathrm{~V}$. The desolvation temperature was set to $600^{\circ} \mathrm{C}$. Nitrogen was used as the desolvation gas ( $800 \mathrm{l} / \mathrm{hour})$ and cone gas $(150 \mathrm{l} / \mathrm{hour})$. Argon was used as the collision gas at a flow rate of $0.15 \mathrm{ml} / \mathrm{min}$. Detection of the ions was performed in the multiple reaction monitoring mode using the transitions described in Table 1. Peak integration and calibrations were performed using TargetLynx software (Version 4.1; Waters).

\section{Unbound Intrinsic Clearance Calculations.}

In vitro. The unbound in vitro $\mathrm{CL}_{\text {int }}\left(\mathrm{CL}_{\text {int }}\right)$ using hepatocytes or microsomes were compared with the in vivo $\mathrm{CL}_{\text {int }}$ values using the regression scaling method (Grime and Riley, 2006). Briefly, the unbound intrinsic clearance was determined using the following equation:

$$
\text { Predicted } \mathrm{CL}_{\text {int } \mathrm{u}}=\left(\left(\mathrm{CL}_{\text {int }} / \mathrm{fu}_{\text {inc }}\right) \times \mathrm{SF} 1 \times \mathrm{SF} 2\right) \times 3 / 1000
$$

where SF1 is the scaling factor for the number of cells per gram of liver $\left(120 \times 10^{6}\right.$ cells/g for humans) or the milligrams of microsomal protein per gram of liver (40 $\mathrm{mg} / \mathrm{g}$ for humans), SF2 is the scaling factor for the liver-to-body weight ratio ( $24 \mathrm{~g} / \mathrm{kg}$ for humans) and $\mathrm{fu}_{\text {inc }}$ is the unbound fraction in the incubation. Note the unbound $\mathrm{CL}_{\text {int }}$ is multiplied by three by way of applying the regression offset correction. Blood clearance $\left(\mathrm{CL}_{\mathrm{b}}\right)$ was calculated using the well-stirred model in the following equation:

$$
\mathrm{CL}_{\mathrm{b}}=\frac{\mathrm{Q} \times \mathrm{CL}_{\text {int } \mathrm{u}} \times \mathrm{fu} / \mathrm{R}_{\mathrm{b} / \mathrm{p}}}{\mathrm{Q}+\mathrm{CL}_{\text {int }} \times \mathrm{fu} / \mathrm{R}_{\mathrm{b} / \mathrm{p}}}
$$

In vivo. The in vivo, observed, unbound intrinsic clearance was calculated from the in vivo plasma clearance values by back calculating through the wellstirred liver model using the following equation:

$$
\begin{aligned}
\mathrm{CL}_{\mathrm{h}} & =\mathrm{CL}-\mathrm{CL}_{\text {renal }} \\
\text { Observed } \mathrm{CL}_{\text {int } \mathrm{u}} & =\frac{\left(\mathrm{CL}_{\mathrm{h}} \times \mathrm{Q}\right)}{\mathrm{fu} \times\left(\mathrm{Q}-\left(\mathrm{CL}_{\mathrm{h}} / \mathrm{R}_{\mathrm{b} / \mathrm{p}}\right)\right)}
\end{aligned}
$$

where $\mathrm{CL}$ is plasma clearance from intravenous or oral studies, $\mathrm{CL}_{\mathrm{h}}$ is the hepatic clearance, $\mathrm{CL}_{\text {renal }}$ is the renal clearance, $\mathrm{Q}$ is hepatic blood flow $(23(\mathrm{ml} / \mathrm{min}) / \mathrm{kg}$ in humans), fu is the plasma protein binding, and $\mathrm{R}_{\mathrm{b} / \mathrm{p}}$ is the blood/plasma ratio. When using the oral clearance values it is assumed that the compound is completely absorbed, and that the liver is the major organ of clearance.

For this study, 10 compounds were selected from the literature where the metabolism has been shown to involve FMO: benzydamine (Taniguchi-Takizawa

TABLE 1

Mass spectrometer parameters for FMO substrates

\begin{tabular}{lcccc}
\hline \multicolumn{1}{c}{ Analyte } & MRM $($ Parent $\rightarrow$ Daughter) $\mathrm{m} / \mathrm{z}$ & Dwell & Cone Voltage & Collision Energy \\
\hline & & $s$ & & $V$ \\
Tamoxifen & $372.166 \rightarrow 129.175$ & 0.080 & 10 & \\
Moclobemide & $269.053 \rightarrow 182.073$ & 0.080 & 10 & 15 \\
Olanzapine & $313.127 \rightarrow 84.118$ & 0.080 & 10 & 25 \\
Imipramine & $281.178 \rightarrow 86.025$ & 0.080 & 60 & 40 \\
Tozasertib & $465.195 \rightarrow 190.215$ & 0.080 & 20 & 15 \\
Ranitidine & $315.095 \rightarrow 176.243$ & 0.040 & 10 & 30 \\
Benzydamine & $310.173 \rightarrow 86.065$ & 0.080 & 60 & 20 \\
Cimetidine & $253.06 \rightarrow 94.994$ & 0.080 & 20 & 40 \\
Clozapine & $327.14 \rightarrow 270.16$ & 0.080 & 40 & 25 \\
Itopride & $359.22 \rightarrow 71.94$ & 0.80 & 10 & \\
Verapamil (IS) & $455.198 \rightarrow 165.207$ & 0.020 & 15 & \\
\hline
\end{tabular}


et al., 2015), imipramine (Adali et al., 1999), olanzapine (Korprasertthaworn et al., 2015), ranitidine (Chung et al., 2000), cimetidine (Cashman et al., 1993), moclobemide (Hoskins et al., 2001), itopride (Mushiroda et al., 2000), clozapine (Tugnait et al., 1997), tamoxifen (Parte and Kupfer, 2005), and tozasertib (Ballard et al., 2007) (Fig. 1).

Determination of FMO Involvement. The contribution of FMO to the intrinsic clearance in HLM was determined using a combination of methimazole competitive substrate inhibition and heat inactivation (Taniguchi-Takizawa et al., 2015). The results of these studies are illustrated in Fig. 2.

The overall FMO contribution was defined as the mean of the inhibition by the competing substrate methimazole $(500 \mu \mathrm{M})$ and the extent of heat inactivation. Both mechanisms give a broadly similar extent of reduction of FMO activity ( $>80 \%$ reduction) as determined by benzydamine $N$-oxide formation. Under the same conditions there was minimal impact $(<30 \%$ reduction in activity) on CYP2B6, CYP2C8, CYP2C9, CYP2C19, CYP2D6, and CYP3A. The impact on CYP1A2 was more significant with $37 \%$ reduction in activity in the presence of methimazole but only $12 \%$ reduction by heat inactivation (for full methods and results, see Supplemental Material).

It was not possible to determine the FMO contribution for ranitidine, cimetidine, olanzapine, and tamoxifen due to the low intrinsic clearance $[<3(\mu \mathrm{l} / \mathrm{min}) / \mathrm{mg}]$ observed in this study (Fig. 2). However, among the remaining six compounds, the greatest FMO contribution was observed with itropride $(>90 \%$ FMO) and the lowest was imipramine ( $20 \%$ FMO). Benzydamine had an FMO contribution of 53\%, moclobemide and tozasertib both had a contribution of $38 \%$, and clozapine had a contribution of $23 \%$.

Human in Vivo Studies. The 10 FMO substrates with human pharmacokinetic data (Fig. 1) were identified from the literature. The plasma

\section{Results}

clearance data for these compounds was combined with the measured plasma protein binding and blood/plasma ratio $\left(\mathrm{R}_{\mathrm{b} / \mathrm{p}}\right)$ to derive the observed unbound $\mathrm{CL}_{\mathrm{int}}$ as described in Materials and Methods (Table 2).

The only compounds in the set with reported significant renal clearance were ranitidine and cimetidine with renal clearances of 7.4 and $6.7(\mathrm{ml} / \mathrm{min}) / \mathrm{kg}$, respectively (Walkenstein et al., 1978; van Hecken et al., 1982). This was incorporated into the calculations, and the derived hepatic clearance was used to calculate the unbound $\mathrm{CL}_{\mathrm{int}}$ as detailed in Materials and Methods. The resulting metabolic component of clearance was calculated to be $1.8(\mathrm{ml} / \mathrm{min}) / \mathrm{kg}$ for ranitidine and $2(\mathrm{ml} / \mathrm{min}) / \mathrm{kg}$ for cimetidine (Table 2).

For olanzapine, itopride, clozapine, and tamoxifen no human intravenous data were available. For these compounds, it was assumed that absorption was complete and that the liver is the major organ of clearance such that the observed oral clearance approximates to the intravenous clearance. This resulted in clearance values of 13.9, 7.6, and $19(\mathrm{ml} / \mathrm{min}) / \mathrm{kg}$, respectively.

Human in Vitro Studies. The in vitro $\mathrm{CL}_{\text {int }}$ was determined for the 10 FMO substrates in human hepatocytes and HLM at a substrate concentration of $1 \mu \mathrm{M}$. The hepatocyte and $\mathrm{HLM} \mathrm{CL}_{\text {int }}$ values ranged from $0.1(\mu \mathrm{l} / \mathrm{min}) / \mathrm{million}$ cells and $<0.3(\mu \mathrm{l} / \mathrm{min}) / \mathrm{mg}$, respectively, for cimetidine to $29.2(\mu \mathrm{l} / \mathrm{min}) /$ million cells and $64.5(\mu \mathrm{l} / \mathrm{min}) / \mathrm{mg}$, respectively, for tozasertib.

The predicted unbound $\mathrm{CL}_{\text {int }}$ was derived by combining the $\mathrm{CL}_{\text {int }}$ with the measured fraction unbound in the incubation and applying the regression correction (eq. 1; Table 3).

For olanzapine, ranitidine, and cimetidine the HLM CL $\mathrm{L}_{\text {int }}$ was beyond the limit of the assay $[<3(\mu \mathrm{l} / \mathrm{min}) / \mathrm{mg}$ protein] so a conservative value of $3(\mu \mathrm{l} / \mathrm{min}) / \mathrm{mg}$ protein was used in the subsequent calculations.

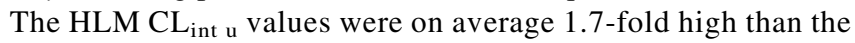
hepatocyte values, although this was influenced by inclusion of olanzapine, ranitidine, and cimetidine, which had HLM $\mathrm{CL}_{\text {int }}$ values

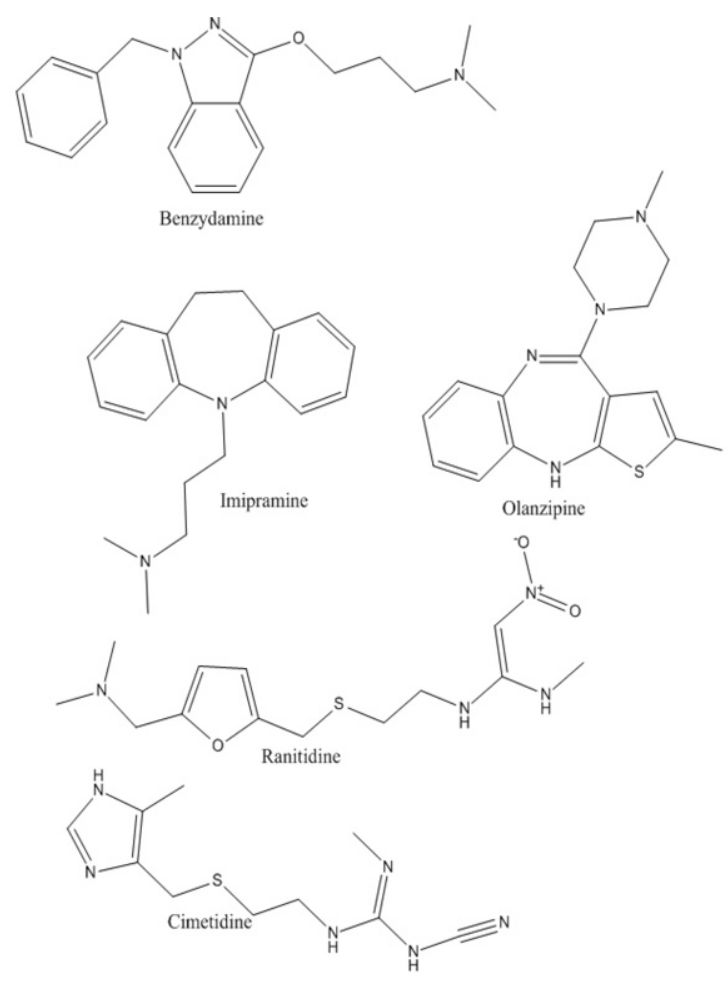

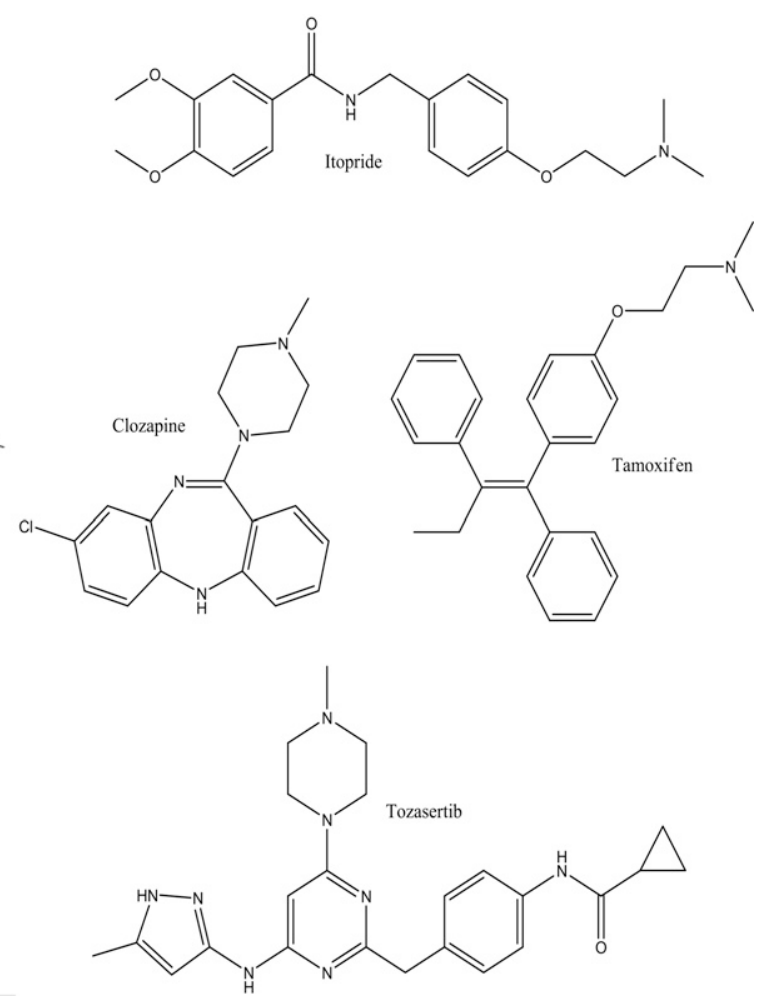

Fig. 1. Structures of the 10 FMO substrates used in the current study. 


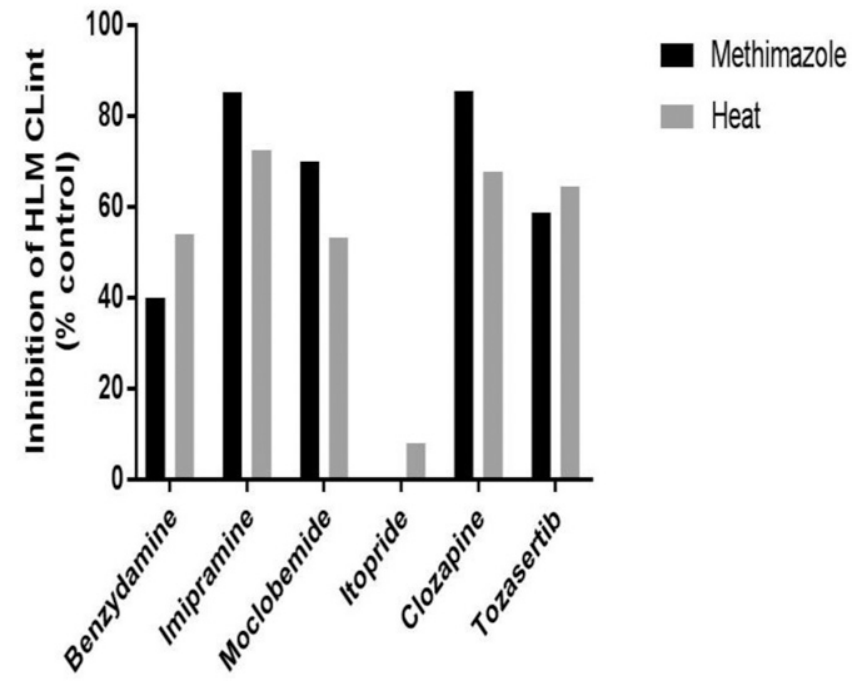

Fig. 2. FMO contribution to microsomal metabolism for the FMO substrates.

set to $3(\mu \mathrm{l} / \mathrm{min}) / \mathrm{mg}$. If these three compounds are omitted from the analysis the then this drops to 0.8 -fold so the unbound $\mathrm{CL}_{\text {int }}$ values from both systems compare very favorably.

Comparison of Predicted and Observed Unbound Intrinsic Clearance. The $\mathrm{CL}_{\text {int }}$ u was calculated for each compound from the hepatocyte or HLM in vitro $\mathrm{CL}_{\text {int }}$ and compared with the corresponding value calculated from $\mathrm{CL}$ values from intravenous or, if no intravenous study was available, from an oral study, assuming a value for the bioavailability. The resulting $\mathrm{CL}_{\mathrm{int}} \mathrm{u}$ values were then compared for each of the systems studied (Fig. 3, A and B; Fig. 4, A and B).

Human hepatocytes produced a good concordance $\left(R^{2}=0.69\right)$ between the predicted and observed unbound intrinsic clearance values, with 8 of 10 compounds falling within or very close to twofold of the line of unity (Fig. 3A). There was also a strong correlation between predicted and observed $\mathrm{CL}_{\mathrm{b}}$ with an $R^{2}$ of 0.75 (Fig. 3B). Benzydamine showed approximately sixfold overprediction in terms of $\mathrm{CL}_{\text {int }}$ u [predicted $\mathrm{CL}_{\text {int } \mathrm{u}}=104(\mathrm{ml} / \mathrm{min}) / \mathrm{kg}$ versus observed $\left.\mathrm{CL}_{\text {int } \mathrm{u}}=18(\mathrm{ml} / \mathrm{min}) / \mathrm{kg}\right]$, which in turn equates to approximately a fourfold over prediction in blood clearance [predicated $\mathrm{CL}_{\mathrm{b}} 11(\mathrm{ml} / \mathrm{min}) / \mathrm{kg}$ versus observed $\mathrm{CL}_{\mathrm{b}} 3(\mathrm{ml} / \mathrm{min}) / \mathrm{kg}$ ]. This is a similar degree of over prediction observed previously (Fisher et al., 2002). In contrast, tozasertib showed an under prediction of around threefold in CLint $\mathrm{u}$ [predicted $\mathrm{CL}_{\text {int } \mathrm{u}}=1177(\mathrm{ml} / \mathrm{min}) / \mathrm{kg}$ versus observed $\mathrm{CL}_{\text {int u }}=3370(\mathrm{ml} / \mathrm{min}) / \mathrm{kg}$ ], which in turn translates to less than twofold in blood clearance [predicted $\mathrm{CL}_{\mathrm{b}}=19(\mathrm{ml} / \mathrm{min}) / \mathrm{kg}$ versus observed $\left.\mathrm{CL}_{\mathrm{b}}=22(\mathrm{ml} / \mathrm{min}) / \mathrm{kg}\right]$.

For HLM, the correlation between the in vitro and in vivo unbound intrinsic clearance values was maintained and also showed a good concordance $\left(R^{2}=0.84\right)$ with only three compounds falling within or close to twofold of the line of unity (Fig. 4A). However, the correlation between predicted and observed $\mathrm{CL}_{\mathrm{b}}(\mathrm{Fig} .4 \mathrm{~B})$ was weaker $\left(R^{2}=0.32\right)$ compared with hepatocytes. Benzydamine produced a greater degree of overprediction in $\mathrm{CL}_{\mathrm{int}} \mathrm{u}$ than was seen with hepatocytes (8-fold) [predicted $\mathrm{CL}_{\text {int u }}=148(\mathrm{ml} / \mathrm{min}) / \mathrm{kg}$ versus observed $\mathrm{CL}_{\text {int u }}=18(\mathrm{ml} / \mathrm{min}) / \mathrm{kg}$ ]. In addition, ranitidine and cimetidine showed significant overpredictions of 4.5 -fold [predicted $\mathrm{CL}_{\text {int u }}=9$ and $9(\mathrm{ml} / \mathrm{min}) / \mathrm{kg}$, respectively, versus observed $\mathrm{CL}_{\text {int u }}=2$ and $2(\mathrm{ml} / \mathrm{min}) / \mathrm{kg}$, respectively]. This is likely due to the overestimation of the in vitro HLM CL $\mathrm{L}_{\text {int }}$, which were set at $3(\mu \mathrm{l} / \mathrm{min}) / \mathrm{mg}$, because the true values were below the limit of quantification of the assay. There was a more significant degree of underprediction in HLM with four compounds (tamoxifen, itopride, tozasertib, and moclobemide) all underpredicted by around sevenfold.

\section{Discussion}

The prediction of human pharmacokinetics is an important part of drug discovery. The use of human in vitro systems such as hepatocytes or HLM combined with the appropriate scaling factors have been routinely used to predict human in vivo CL (Riley et al., 2005; Di et al., 2013).

It has been shown that not all enzyme systems are fully recovered when the in vitro preparation is produced from the original tissue. Specifically, AO activity has been shown to be lower in isolated in vitro systems compared with the original tissue (Hutzler et al., 2014). This reduced activity significantly impaired the ability of these in vitro systems to predict adequately the clearance of a set of AO substrates (Zientek et al., 2010). The current study determined the in vitro $\mathrm{CL}_{\text {int }}$ values in hepatocytes and HLM for a set compounds that had differential degrees of FMO involvement in their metabolism. The aim was to determine whether FMOs were subject to similar recovery issues, because $\mathrm{AO}$ and the potential downstream consequences for the prediction on in vivo CL.

The 10 compounds used here have all been shown to have metabolic routes that are mediated by FMO. Generally, FMO investigations have been related to specific metabolic pathways such as the $N$-oxygenation of moclobemide (Hoskins et al., 2001) without necessarily looking at the contribution the pathway makes to the overall hepatic in vitro $\mathrm{CL}_{\text {int }}$. When this was determined for 6 of the 10 FMO substrates in this study,

TABLE 2

Human in vivo plasma clearance, plasma protein, and blood plasma ratio data for $10 \mathrm{FMO}$ substrates

\begin{tabular}{lccccl}
\hline & CL i.v. or oral & $\mathrm{fu}$ & $\mathrm{R}_{\mathrm{b} / \mathrm{p}}$ & Observed $\mathrm{CL}_{\mathrm{int} \mathrm{u}}$ & \multicolumn{1}{c}{ Reference } \\
\hline & $(\mathrm{ml} / \mathrm{min}) / \mathrm{kg}$ & & & $(\mathrm{ml} / \mathrm{min}) / \mathrm{kg}$ & \\
Benzydamine & $2.3^{a}$ & 0.148 & 0.76 & 18 & Baldock et al. (1991) \\
Imipramine & 12.8 & 0.221 & 0.93 & 192 & Abernethyl et al. (1984) \\
Olanzapine & $6.2^{b}$ & 0.294 & 0.73 & 30 & Callaghan et al. (1999) \\
Ranitidine & $1.8^{a, c}$ & 0.874 & 0.90 & 2 & van Hecken et al. (1982) \\
Cimetidine & $2^{a, c}$ & 0.899 & 1.02 & 2 & Walkenstein et al. (1978) \\
Moclobemide & $13.2^{a}$ & 0.622 & 0.84 & 61 & Raaflaub et al. (1984) \\
Itopride & $13.9^{b}$ & 0.246 & 0.72 & 296 & Cho et al. (2010) \\
Clozapine & $7.6^{b}$ & 0.106 & 0.83 & 131 & Tassaneeyakul et al. (2005) \\
Tamoxifen & $1.9^{b}$ & 0.0003 & 0.89 & 4293 & Fuchs et al. (1996) \\
Tozasertib & $20.7^{a}$ & 0.076 & 0.94 & 3370 & Traynor et al. (2011) \\
\hline
\end{tabular}

${ }^{a}$ From intravenous study.

${ }^{b}$ From oral study.

${ }^{c}$ Corrected for renal clearance. 
TABLE 3

Human in vitro data for 10 FMO substrates

All data $\mathrm{n}=3$ except for data marked with *, which is $\mathrm{n}=2$.

\begin{tabular}{|c|c|c|c|c|c|c|c|c|}
\hline & \multicolumn{4}{|c|}{ Human Hepatocytes } & \multicolumn{4}{|c|}{ Human Liver Microsomes } \\
\hline & $\mathrm{CL}_{\text {int }}$ & $\mathrm{fu}_{\mathrm{inc}}{ }^{a}$ & Predicted $\mathrm{CL}_{\text {int u }}$ & Predicted $\mathrm{CL}_{\mathrm{b}}$ & $\mathrm{CL}_{\text {int }}$ & $\mathrm{fu}_{\mathrm{inc}}$ & Predicted $\mathrm{CL}_{\text {int u }}$ & Predicted $\mathrm{CL}_{\mathrm{b}}$ \\
\hline & $(\mu \mathrm{l} / \mathrm{min}) / 10^{6} \mathrm{cells}$ & & & $1 / \min ) / \mathrm{kg}$ & & & $(\mathrm{ml} / \mathrm{mi}$ & n) $/ \mathrm{kg}$ \\
\hline Benzydamine & 9 & 0.74 & 104 & 11 & 18 & 0.35 & 148 & 13 \\
\hline Imipramine & 9 & 0.65 & 122 & 13 & 14 & 0.31 & 129 & 13 \\
\hline Olanzapine & 2 & 0.86 & 18 & 5 & $<3^{b}$ & 0.73 & 12 & 4 \\
\hline Ranitidine & $0.6^{*}$ & 0.98 & 5 & 4 & $<3^{b}$ & 0.97 & 9 & 6 \\
\hline Cimetidine & $0.1^{*}$ & 1.01 & 1 & 1 & $<3^{b}$ & 1.01 & 9 & 6 \\
\hline Moclobemide & 3 & 0.87 & 30 & 11 & 3 & 0.98 & 9 & 5 \\
\hline Itopride & 11 & 0.88 & 107 & 14 & 18 & 1.05 & 49 & 10 \\
\hline Clozapine & 5 & 0.33 & 131 & 10 & 18 & 0.30 & 173 & 11 \\
\hline Tamoxifen & 4 & 0.00 & 9706 & 3 & 4 & 0.02 & 662 & 0.2 \\
\hline Tozasertib & 29 & 0.21 & 1177 & 19 & 61 & 0.18 & 971 & 18 \\
\hline
\end{tabular}

${ }^{a}$ Data from rat hepatocytes.

${ }^{b}$ Value of $3(\mu \mathrm{l} / \mathrm{min}) / \mathrm{mg}$ used in calculations.

the FMO contribution was seen to vary from itopride $(>90 \%)$ to imipramine and clozapine, where the FMO contribution is just over $20 \%$. This reflects the situation seen in many drug discovery programs where the contribution to hepatic metabolism for any given enzyme will vary across compounds.

This study demonstrated consistency when scaling FMO substrates from either hepatocytes or HLM. It has been argued that hepatocytes are the most suitable system to use for scaling clearance because of the presences of the full complement of drug metabolizing enzymes (Riley et al., 2005). This aspect is important for compounds such as olanzapine, which have been shown to form phase 2 metabolites, such as $N$-glucuronides, which would not be seen and so accounted for in the HLM (Korprasertthaworn et al., 2015). Interestingly, in this study olanzapine predicted clearance equally well from both hepatocytes and HLM, suggesting that the $\mathrm{N}$-glucuronide is not playing a major role in the rate of metabolism in these systems.

The only compound that was significantly overpredicted in both hepatocyte and HLM was benzydamine. This was also the case in HLM. This was observed previously by Fisher et al. (2002) who speculated that the reported intravenous human pharmacokinetics may be in error possibly due to enterohepatic recycling of the $N$-oxide metabolite, an analytical error or an unknown enhancement of FMO activity in the in vitro systems. The potential for the $N$ - or S-oxide to be reduced back to the original drug molecule in vivo would confound this type of in vitro-in vivo assessment and lead to an underprediction of in vivo $\mathrm{CL}_{\mathrm{int}}$. It has been shown that both imipramine and desipramine are circulating in the plasma of healthy volunteers after intravenous, intramuscular, and oral dosing of imipramine $\mathrm{N}$-oxide (Nagy and Hansen, 1978). Whether one of these reasons or a different reason is behind the underprediction of benzydamine is unclear.

FMOs are differentially distributed in the body with FMO3 and FMO5 expressed in the liver and FMO1 and FMO2 mainly expressed in the kidney and lung, respectively (Cashman and Zhang, 2006). Hence, studies that use human hepatocytes and HLM will reflect the involvement of FMO3, and to a lesser extent FMO5, but not FMO1 and FMO2. As such these studies may underestimate the contribution of FMO to the overall clearance of a compound if the latter two enzymes play a significant role in its metabolism. However, based on the $S$-oxygenation of a disulfiram metabolite, it has been estimated that the human kidney has 14-fold lower FMO metabolic capacity compared
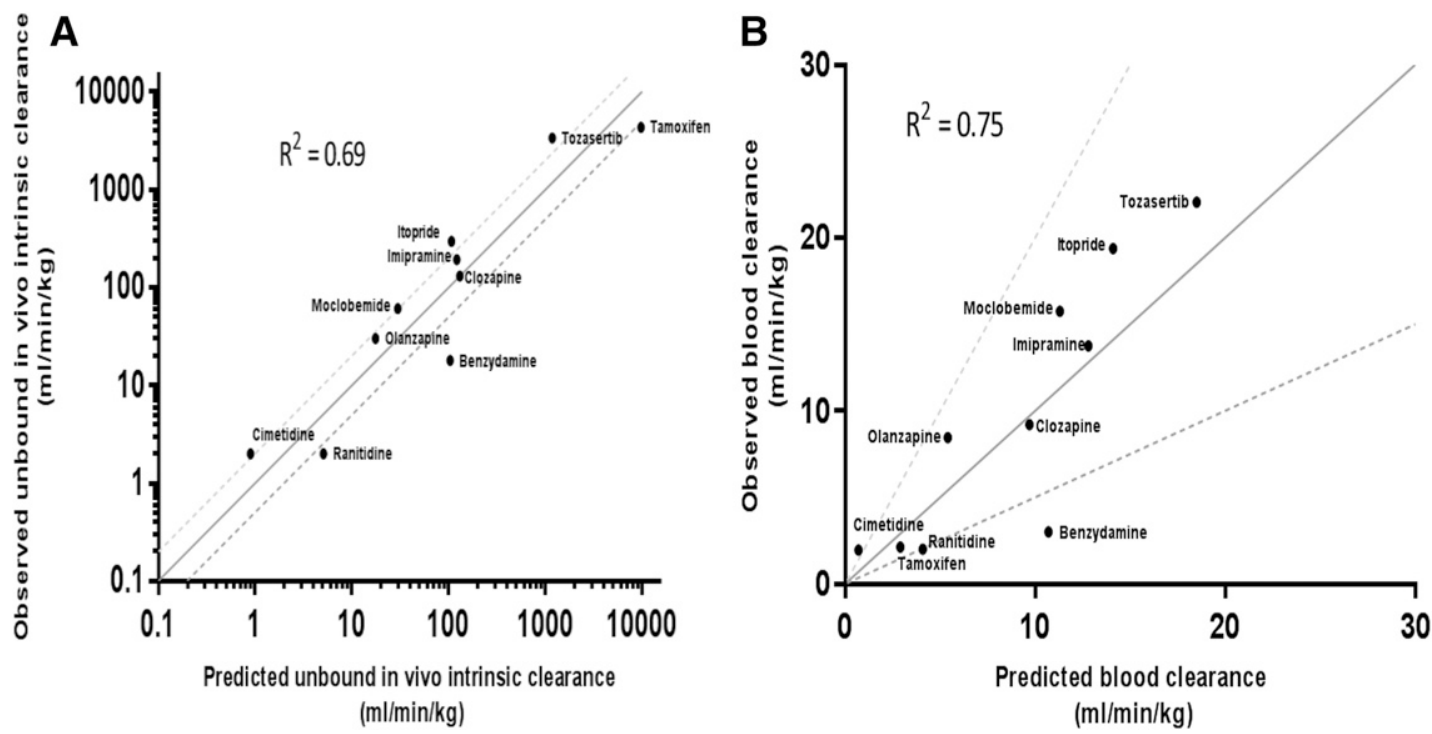

Fig. 3. Unbound intrinsic clearance in vitro/in vivo correlation (A) and blood in vitro/in vivo clearance (B) correlations for human hepatocytes. 


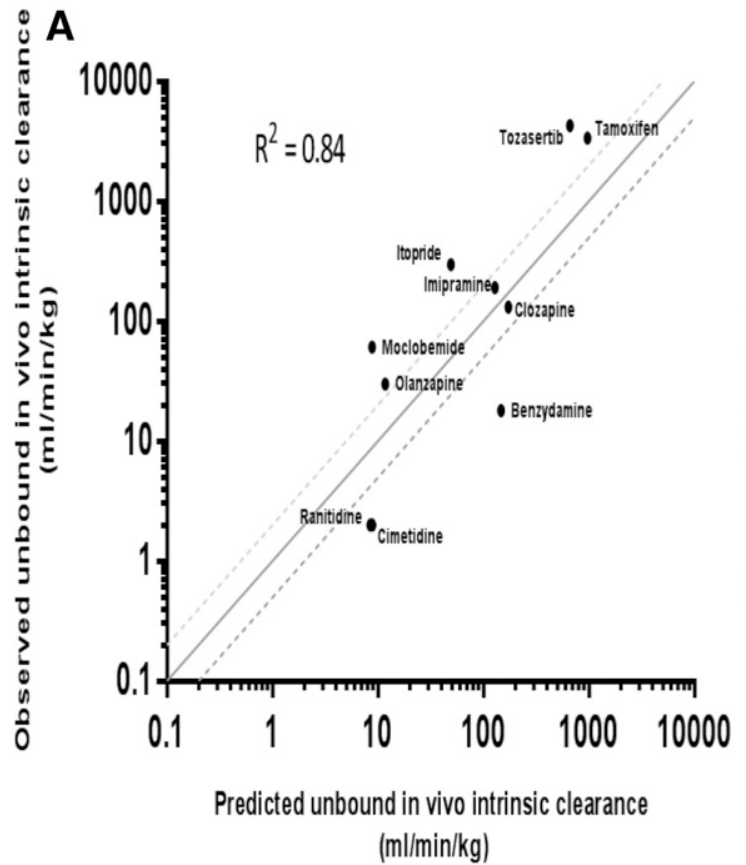

B

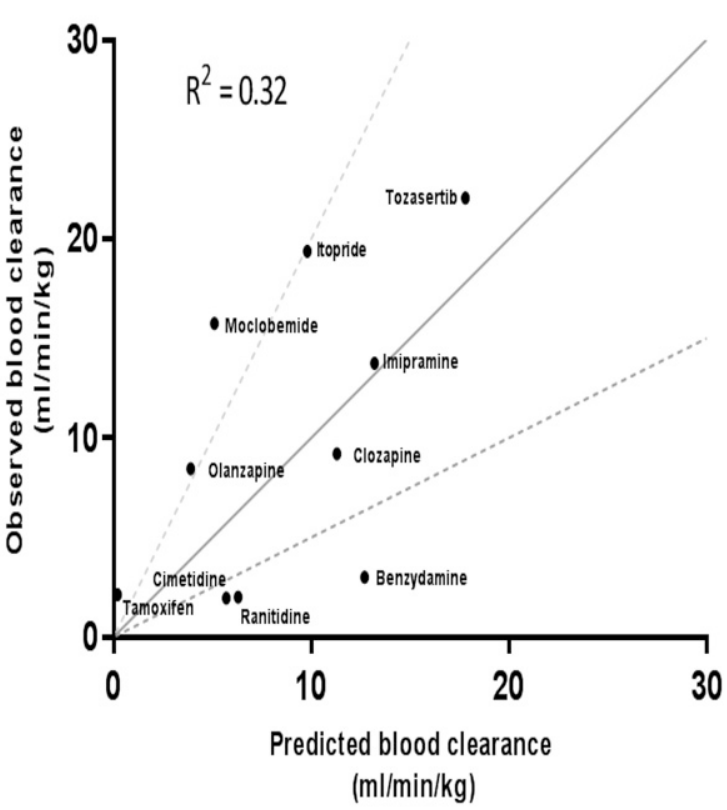

Fig. 4. Unbound intrinsic clearance in vitro/in vivo correlation (A) and blood in vitro/in vivo clearance (B) correlations for human liver microsomes.

with the liver so the impact of FMO1 may not be highly significant (Cashman and Zhang, 2006).

In general, HLM did not perform as well as hepatocytes in predicting $\mathrm{CL}_{\mathrm{b}}$ in this study, supporting the view that the intact hepatocyte is a better system for predicting human clearance. There were a number of compounds that were both over- and underpredicted. The reason for this is not clear but may relate to other clearance mechanisms not reflected in HLM or low recovery of the microsomal clearance enzymes after cryopreservation.

The approach adopted in this study uses point estimates for the scaling factors - the number of cells per gram of liver or the milligrams of microsomal protein per gram of liver and the liver-to-body weight ratio. This does not take into account the population variability in these scaling factors, which in turn can lead to variability in the subsequent clearance estimates (Kenyon et al., 2016). However, in the context of drug discovery where the challenge is to optimize and select a small number of drug molecules from hundreds of compounds, it can be argued that using such point estimates can facilitate this selection, because it reduces the number of parameters contributing to the overall variability to those related to the molecule and not to the system. While this allows rank ordering of compounds, it does not give a full understanding of the variability in clearance that might occur in vivo. Once compounds are selected, then it is appropriate to use more sophisticated approaches such as physiologically based pharmacokinetic modeling to account for variability in these scaling factors along with the variability in other system-related parameters such as the variability in the enzyme expression. This is also important for FMO3, in particular given the polymorphic nature of its expression (Cashman and Zhang, 2006). At this stage it is also important to consider the variability that might be seen in pediatric populations, because it is reported that FMO1 is expressed in the liver up to 72 hours postnatally when it is suppressed, whereas FMO3 expression increases in a variable manner until full expression is reached around 10 years of age (Hines and McCarver, 2002). Thus the physiologically based pharmacokinetic approach will give a much greater understanding of the anticipated overall variability in clearance that could be seen in vivo.
This study clearly demonstrates, with a range of substrates, that the routine methodologies employed to scale in vitro metabolic data to in vivo clearance adequately capture and scale the activity of FMO.

\section{Authorship Contributions}

Participated in research design: Jones, Srivastava, Reddy, Colclough.

Conducted experiments: Srivastava, Amberntsson, Li.

Performed data analysis: Jones, Srivastava, Colclough, Wilson, Reddy, Amberntsson, Li.

Wrote or contributed to the writing of the manuscript: Jones, Srivastava, Colclough, Wilson, Reddy, Amberntsson, Li.

\section{References}

Abernethyl DR, Divoll M, Greenblatt DJ, Harmatz JS, and Shader RI (1984) Absolute bioavailability of imipramine: influence of food. Psychopharmacology (Berl) 83:104-106.

Adali O, Carver GC, and Philpot RM (1999) The effect of arginine-428 mutation on modulation of activity of human liver flavin monooxygenase 3 (FMO3) by imipramine and chlorpromazine. Exp Toxicol Pathol 51:271-276.

Baldock GA, Brodie RR, Chasseaud LF, Taylor T, Walmsley LM, and Catanese B (1991) Pharmacokinetics of benzydamine after intravenous, oral, and topical doses to human subjects. Biopharm Drug Dispos 12:481-492.

Ballard JE, Prueksaritanont T, and Tang C (2007) Hepatic metabolism of MK-0457, a potent aurora kinase inhibitor: interspecies comparison and role of human cytochrome P450 and flavincontaining monooxygenase. Drug Metab Dispos 35:1447-1451.

Bonn B, Svanberg P, Janefeldt A, Hultman Ia, and Grime K (2016) Determination of human hepatocyte intrinsic clearance for slowly metabolized compounds: comparison of a primary hepatocyte/stromal cell co-culture with plated primary hepatocytes and HepaRG. Drug Metab Dispos 44:527-533.

Callaghan JT, Bergstrom RF, Ptak LR, and Beasley CM (1999) Olanzapine. Pharmacokinetic and pharmacodynamic profile. Clin Pharmacokinet 37:177-193.

Cashman JR and Zhang J (2006) Human flavin-containing monooxygenases. Annu Rev Pharmacol Toxicol 46:65-100.

Cashman JR, Park SB, Yang ZC, Washington CB, Gomez DY, Giacomini KM, and Brett CM (1993) Chemical, enzymatic, and human enantioselective S-oxygenation of cimetidine. Drug Metab Dispos 21:587-597.

Cho KJ, Cho W, Cha KH, Park J, Kim MS, Kim JS, and Hwang SJ (2010) Pharmacokinetic and bioequivalence study of itopride $\mathrm{HCl}$ in healthy volunteers. Arzneimittelforschung 60:137-140. Chung WG, Park CS, Roh HK, Lee WK, and Cha YN (2000) Oxidation of ranitidine by isozymes of flavin-containing monooxygenase and cytochrome P450. Jpn J Pharmacol 84:213-220.

Di L, Feng B, Goosen TC, Lai Y, Steyn SJ, Varma MV, and Obach RS (2013) A perspective on the prediction of drug pharmacokinetics and disposition in drug research and development. Drug Metab Dispos 41:1975-1993.

Fiorentini F, Geier M, Binda C, Winkler M, Faber K, Hall M, and Mattevi A (2016) Biocatalytic characterization of human FMO5: unearthing Baeyer-Villiger reactions in humans. ACS Chem Biol 11:1039-1048. 
Fisher MB, Yoon K, Vaughn ML, Strelevitz TJ, and Foti RS (2002) Flavin-containing monooxygenase activity in hepatocytes and microsomes: in vitro characterization and in vivo scaling of benzydamine clearance. Drug Metab Dispos 30:1087-1093.

Fuchs WS, Leary WP, van der Meer MJ, Gay S, Witschital K, and von Nieciecki A (1996) Pharmacokinetics and bioavailability of tamoxifen in postmenopausal healthy women. Arzneimittelforschung 46:418-422.

Geier M, Bachler T, Hanlon SP, Eggimann FK, Kittelmann M, Weber H, Lütz S, Wirz B, and Winkler M (2015) Human FMO2-based microbial whole-cell catalysts for drug metabolite synthesis. Microb Cell Fact 14:82.

Grime K and Riley RJ (2006) The impact of in vitro binding on in vitro-in vivo extrapolations, projections of metabolic clearance and clinical drug-drug interactions. Curr Drug Metab 7: 251-264.

Grime KH, Barton P, and McGinnity DF (2013) Application of in silico, in vitro and preclinical pharmacokinetic data for the effective and efficient prediction of human pharmacokinetics. Mol Pharm 10:1191-1206.

Hines RN and McCarver DG (2002) The ontogeny of human drug-metabolizing enzymes: phase I oxidative enzymes. $J$ Pharmacol Exp Ther 300:355-360.

Hoskins J, Shenfield G, Murray M, and Gross A (2001) Characterization of moclobemide N-oxidation in human liver microsomes. Xenobiotica 31:387-397.

Hutzler JM, Yang YS, Brown C, Heyward S, and Moeller T (2014) Aldehyde oxidase activity in donor-matched fresh and cryopreserved human hepatocytes and assessment of variability in 75 donors. Drug Metab Dispos 42:1090-1097.

Kenyon EM, Eklund C, Lipscomb JC, and Pegram RA (2016) The impact of variation in scaling factors on the estimation of internal dose metrics: a case study using bromodichloromethane (BDCM). Toxicol Mech Methods 26:620-626.

Kim YM and Ziegler DM (2000) Size limits of thiocarbamides accepted as substrates by human flavin-containing monooxygenase 1. Drug Metab Dispos 28:1003-1006.

Korprasertthaworn P, Polasek TM, Sorich MJ, McLachlan AJ, Miners JO, Tucker GT, and Rowland A (2015) In vitro characterization of the human liver microsomal kinetics and reaction phenotyping of olanzapine metabolism. Drug Metab Dispos 43:1806-1814.

Krueger SK, Vandyke JE, Williams DE, and Hines RN (2006) The role of flavin-containing monooxygenase (FMO) in the metabolism of tamoxifen and other tertiary amines. Drug Metab Rev 38:139-147.

Mushiroda T, Douya R, Takahara E, and Nagata O (2000) The involvement of flavin-containing monooxygenase but not CYP3A4 in metabolism of itopride hydrochloride, a gastroprokinetic agent: comparison with cisapride and mosapride citrate. Drug Metab Dispos 28:1231-1237.

Nagy A and Hansen T (1978) The kinetics of imipramine-N-oxide in man. Acta pharmacologica et toxicologica 42:58-67.
Parte P and Kupfer D (2005) Oxidation of tamoxifen by human flavin-containing monooxygenase (FMO) 1 and FMO3 to tamoxifen-N-oxide and its novel reduction back to tamoxifen by human cytochromes P450 and hemoglobin. Drug Metab Dispos 33:1446-1452.

Phillips IR and Shephard EA (2008) Flavin-containing monooxygenases: mutations, disease and drug response. Trends Pharmacol Sci 29:294-301.

Raaflaub J, Haefelfinger P, and Trautmann KH (1984) Single-dose pharmacokinetics of the MAOinhibitor moclobemide in man. Arzneimittelforschung 34:80-82

Riley RJ, McGinnity DF, and Austin RP (2005) A unified model for predicting human hepatic, metabolic clearance from in vitro intrinsic clearance data in hepatocytes and microsomes. Drug Metab Dispos 33:1304-1311.

Taniguchi-Takizawa T, Shimizu M, Kume T, and Yamazaki H (2015) Benzydamine N-oxygenation as an index for flavin-containing monooxygenase activity and benzydamine $\mathrm{N}$-demethylation by cytochrome $\mathrm{P} 450$ enzymes in liver microsomes from rats, dogs, monkeys, and humans. Drug Metab Pharmacokinet 30:64-69.

Tassaneeyakul W, Kittiwattanagul K, Vannaprasaht S, Kampan J, Tawalee A, Puapairoj P, Tiamkao S, Juthagridsada S, Kukongviriyapan V, and Tassaneeyakul W (2005) Steady-state bioequivalence study of clozapine tablet in schizophrenic patients. J Pharm Pharm Sci 8:47-53.

Traynor AM, Hewitt M, Liu G, Flaherty KT, Clark J, Freedman SJ, Scott BB, Leighton AM, Watson PA, Zhao B, et al. (2011) Phase I dose escalation study of MK-0457, a novel Aurora kinase inhibitor, in adult patients with advanced solid tumors. Cancer Chemother Pharmacol 67: $305-314$.

Tugnait M, Hawes EM, McKay G, Rettie AE, Haining RL, and Midha KK (1997) N-oxygenation of clozapine by flavin-containing monooxygenase. Drug Metab Dispos 25:524-527.

van Hecken AM, Tjandramaga TB, Mullie A, Verbesselt R, and de Schepper PJ (1982) Ranitidine: single dose pharmacokinetics and absolute bioavailability in man. Br J Clin Pharmacol 14: 195-200.

Walkenstein SS, Dubb JW, Randolph WC, Westlake WJ, Stote RM, and Intoccia AP (1978) Bioavailability of cimetidine in man. Gastroenterology 74:360-365.

Zientek M, Jiang Y, Youdim K, and Obach RS (2010) In vitro-in vivo correlation for intrinsic clearance for drugs metabolized by human aldehyde oxidase. Drug Metab Dispos 38: $1322-1327$.

Address correspondence to: Barry Jones, Hodgkin Bldg c/o B310, Cambridge Science Park, Milton Rd., Cambridge, Cambridgeshire, CB4 OWG UK. E-mail: Barry.Jones1@astrazeneca.com 